\title{
Entrepreneurs, Strategy, Venturing Process and Industry Environment: A Configurational Approach to New Venture Emergence
}

\author{
Qian $\mathrm{Ye}^{1}$ \\ ${ }^{1}$ Business Department, University of Wisconsin Parkside, Kenosha, U.S.A \\ Correspondence: Qian Ye, Business Department, University of Wisconsin Parkside, 900 Wood Road, Kenosha, \\ WI, 53141-2000. E-mail: ye@uwp.edu
}

Received: December 6, 2016

Accepted: January 26, $2017 \quad$ Online Published: February 15, 2017

doi:10.5539/ibr.v10n3p148

URL: https://doi.org/10.5539/ibr.v10n3p148

\begin{abstract}
This study applied qualitative comparative analysis (QCA) as a viable method for new venture emergence. Through the inclusion of four-dimension variables from individuals, founding strategy, startup process, and environment, the study illuminates the importance of factor independence, factor interdependence, and factor complex causality in understanding new venture emergence. This study demonstrates the benefits of QCA approach to entrepreneurship research, a complement to the conventional variance-based approach. Limitations of QCA and future research directions are provided.
\end{abstract}

Keywords: new venture emergence, new venture creation, entrepreneurship, nascent entrepreneurs, venturing process, configuration, QCA

\section{Introduction}

New venture emergence is a complex and multidimensional phenomenon (Low \& MacMillan, 1988). It remains one of the most prominent and enduring research questions in the field of entrepreneurship (Low \& Abrahamson, 1997; Aldrich, 2012). A fundamental question of this line of research is what factors contribute to emergence variations. Previous theoretical and empirical researches from different standpoints have improved our knowledge of new venture emergence (Gartner, 1985; Shook, Priem, \& McGee, 2003; Brush, Manolova, \& Edelman, 2008; Jones \& Holt, 2008). However, it has also shown that this phenomenon is much more complex and heterogeneous than was thought (Lichtenstein, Carter, Dooley, \& Gartner, 2007). The extant literature has not found consistent patterns that are common to all emerging organizations.

Back to as early as 1980 s, Gartner (1985) proposed a framework that describes new venture emergence as a process that involves four dimensions of factors: individuals, venturing process, organizational structure and strategies, and environmental contexts. Factors in the four dimensions are interdependent to each other, forming various configurations that have non-linear effects on venturing outcomes (Lichtenstein et al., 2007). A question arises: what types of configurations best explain new venture emergence? To address this question, this study applied a qualitative comparative analysis technique (QCA), an alternative approach grounded in classical set theory to the traditional variance-based research, to examine the interdependence of determining factors and its casual effects on venture formation. QCA conceptualizes cases as combinations of attributes that lead to unique outcomes (Ragin, 1987, 2000; Fiss, 2007). Compared with the methods used by traditional research, QCA focuses on configurations of factors that lead emergence of new ventures, rather than focusing on specific explanatory factors themselves. It has a few advantages. First, QCA assumes nonlinear relationships and complex causality of factors that lead venture emergence, which goes beyond traditional method that examines bivariate interaction effects of influential factors. Second, it addresses equifinality which assumes that two or more configurations of venture gestation process can be equally effective in venture emergence. Finally, at the center of QCA lies Boolean algebra that determines various combinations of variables from different levels that result in new venture emergence. QCA allows to answer a question "How various factors at individual, firm, and environmental levels are combined together impacting new venture emergence?" that the traditional regression models hardly solve.

The rest of the paper first reviews factors that were found to impact new venture emergence, and presents the limitations of conventional configurational approach and the advantages of QCA approach to new venture emergence. Next, the author analyzes and reports the results of the diversity and causal complexity underlying 
venture formation, using a sample of nascent entrepreneurs from the Panel Study of Entrepreneurial Dynamics (PSED). Discussion and conclusion are included in the end.

\section{Literature Review and Theoretical Framework}

\subsection{Toward a Configurational Theory of New Venture Emergence}

New venture emergence is a complicated and dynamic phenomenon that involves numerous preparatory activities and decisions. Gartner (1985) outlined a four-dimensional framework that includes individual characteristics, venturing activities, strategy, and environments. A new venture, as an organizational entity, evolves overtime rather than being produced instantaneously. The startup process begins with a set of actions taken by nascent entrepreneurs, and ends with an independent entity established. During this process, individuals identify and refine business ideas, seek out resources, pursue specific strategies, and make the first entry into the marketplace. The emergence of new venture is a person-environment interactions (Korunka, Frank, Lueger, \& Mugler, 2003; Chuang, Hsu, Wang, \& Judge, 2015; Aragon-Mendoza, Raposo, \& Roig-Dobón, 2016). Entrepreneurs and their expertise are key elements to venturing outcomes. Specific types of events, or organizing activities occur in a temporally complex and nonlinear manner (Lichtenstein et al., 2007), and they are rooted within a context of its environment (Gartner, 1985). Thus, examining unidimensional and a single aspect of new venture emergence only palpates different parts of the elephant (Gartner, 1985). Without showing the complexity, heterogeneity, and multidimensional nature, it is not possible to provide a completed insight into the phenomenon.

The promising basis of multi-facet theory of new venture emergence could be found in the configuration approach that goes beyond the concepts of unidirectional causal relationships. Configurations is defined as "any multidimensional constellation of conceptually distinct characteristics that commonly occur together" (Meyer, Tsui, \& Hinings, 1993:1175). Researchers advocate configurational approach as an important way to improve understanding and theory building ( i.e., Doty \& Glick, 1994). In essence, a configurational approach suggests that venture emergence is best understood as clusters of interconnected behaviors, practices and contexts, rather than as various components loosely coupled. A configurational approach therefore takes a systematic and holistic view of the process, where patterns rather than individual independent variables are related to the outcome. The outcome of startup efforts of an emerging venture depend on the individual, structural, strategic, and contextual variables. There is a growing body of research has explored the mutual interdependent relationships of new venture emergence. For example, firm formation has been examined in the contingency of founder attributes (Phillips, Tracey, \& Karra, 2013), startup activities (Gatewood, Shaver, \& Gartner, 1995), founding strategies (Gartner, Starr, \& Bhat, 1999), and environments (Gartner \& Liao, 2012). However, only a few empirical studies have adopted a configurational approach to understand the "fit" among multiple contingent variables. For instance, using the configurational approach, Korunka et al. (2003) examined the personality of nascent entrepreneurs in the startup process. They revealed three configurations that are composed with different patterns of personality characteristics interpreted in the context of environment, resources, and startup process.

Drawing on Gartner's framework, in the following sessions, this paper discusses how new venture emergence evolves from person-process-firm-environment interactions, specifically, how new venture emergence is affected by individual's attributes, venturing activities, startup strategies, and environments. The mutual interdependent relationships of new venture emergence are shown in the diagram.

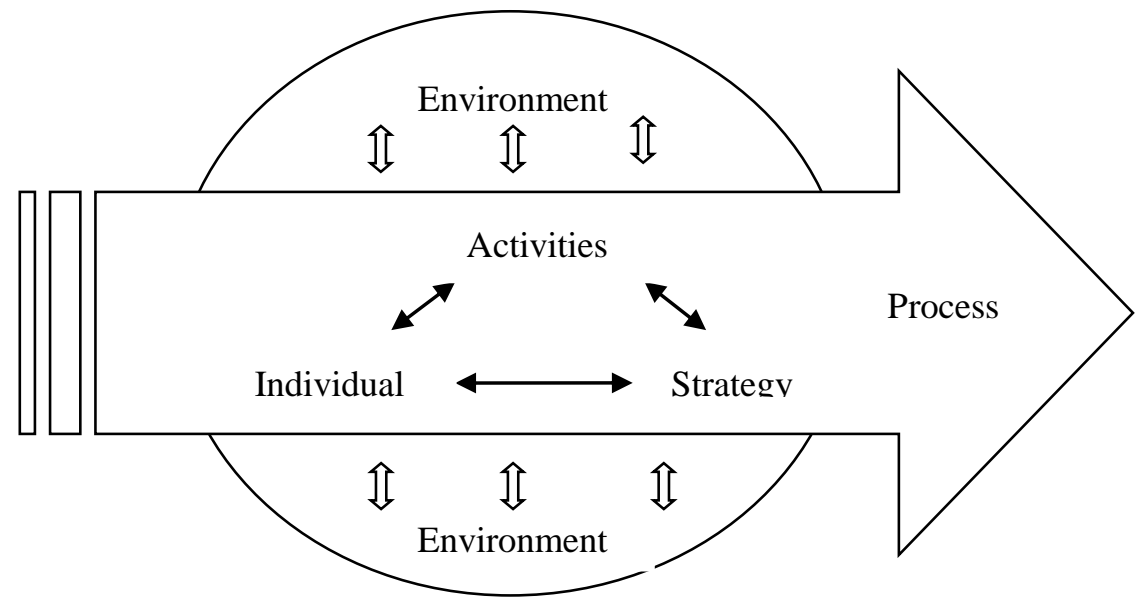

Figure 1. The process of new venture creation is rooted within its context of environment 


\subsubsection{The Individual Characteristics - Entrepreneurs (E)}

It has been broadly accepted that entrepreneur is the core element for venture emergence. New venture is created by nascent entrepreneurs who have a set of particular characteristics. The extant literature provides a whole array of entrepreneurs' characteristics that matter for new venture emergence, among which three individual characteristics are mostly documented: personal experience (Gartner et al., 1999; Davidsson \& Honig, 2003), family background of self-employment (Brüderl, Preisendörfe, \& Ziegler, 1992), and the presence of entrepreneurial team (Klotz, Hmieleski, Bradley, \& Busenitz, 2014).

Individuals are the central agent of new venture creation (Eckhardt \& Shane, 2013). Entrepreneurs' prior knowledge and experiences are critical factors for venture emergence (Gruber, MacMillan, \& Thompson, 2013). Some knowledge necessary to firm establishment generally is obtained from personal past experience. Founders with richer prior experience of startups are able to recognize attractive business opportunities, and have greater knowledge of successfully setting up a business (Brüderl et al., 1992). A broad set of skills and expertise exhibited by nascent entrepreneurs has been found to be positively related to success startups (Van de Ven, Hudson, \& Schroeder, 1984). Carter et al. (1997) found that experience of starting other businesses, industry experience, starting a business with partners, and having employees all significantly decrease the odds of discontinuance of venturing.

Entrepreneur's family background is also an important determinant for new venture emergence. People create their own business might have obtained necessary knowledge and skills from role models of their self-employed parents (Brüderl et al., 1992). Research also suggests that people grow up in these families perceive entrepreneurship as more viable career than those do not have such family backgrounds (Shapero \& Giglierano, 1982). In addition, individuals who come from families with self-owned businesses background have higher social capital and stronger bonding ties that assist information transfer and knowledge accumulation, therefore these people are more likely to discover opportunities than those do not (Davidsson \& Honig, 2003).

Entrepreneurial team is another important factor that determines the success of venture formation (Klotz et al., 2014). When individual entrepreneurs form a team, they bring various knowledge, skills, and competencies therefore the team has advantages of gathering information required for business venturing (Cooper \& Daily, 1997). Entrepreneurial teams verify the validity of business ideas better (Cooper \& Daily, 1998), and have more completed knowledge than their solo counterparts (Forbes, Borchert, Zellmer-Bruhn, \& Sapienza, 2006).

Drawing on the above evidence, it can reasonably assume that if an entrepreneur has rich startup experiences; or has grown up in a family whose parents are self-employed; or starts a venture with other people, he/she should be more successful in venture creation than those do not. However, current empirical studies do not provided conclusive findings. For example, specific entrepreneurial experiences are found to be related to both venture performance and survival in some studies ( i.e. Gimeno, Folta, Cooper, \& Woo, 1997), but not in others (Brüderl et al., 1992; Davidsson \& Honig, 2003; Haber \& Reichel, 2007). The inconsistent results may due to the fact that there is no fixed rules that skills and knowledge gained from prior experience or observed others during growing up period will be definitely transferred into subsequent founding process (Alsos \& Kolvereid, 1998). The lessons learned by individual entrepreneurs are highly contextual dependent. The learning capacities of entrepreneurs and their abilities to involve themselves in the changing circumstances are also various across individuals (Cope, 2005). Entrepreneurs either learn from their past experience or do not. In addition, it is possible that the knowledge and skills obtained from past startup experiences will hinder the success of establishing a new organizational entity if competitive dynamics of an industry have changed but these changes are not recognized (Starr \& Bygrave, 1991).

\subsubsection{The Venturing Activities - Processes $(\mathrm{P})$}

What entrepreneurs do in the venturing process is another critical determinant of venture emergence (Carter, Gartner, \& Reynolds, 1996). Venturing activities include obtaining resources, developing new products, seeking funding, doing sales and hiring employees etc. The extant literature suggests significant variations exist in the number of activities reported, the sequence of activities, and the amount of time between activity events in the dynamic and complex venturing process (Reynolds \& Miller, 1992). The rate of organizing, concentration, and timing have direct impacts on new venture emergence (Lichtenstein et al., 2007). Not all startup activities are needed for the entrepreneurs or founding teams. For example, if an entrepreneur has inherited money, there is no need to seek external financial support. The patterns of startup activities also vary due to individual demographic, cognitive, or psychological attributes. Entrepreneurs have limited cognitive capabilities and may not possibly engage in all startup activities simultaneously. They have to make intentional choices to reach maximum utilization of limited resources. As a result, there may be a high degree of variation in terms of which activities they undertake first and which later. In addition, the ability to undertake certain activities depends on the 
completion of other activities. For instance, a contract with a major customer would enable an entrepreneur to secure a capital infusion from venture capitalists. Venkataraman et al (1990) referred it as a leveraging strategy in which a set of transactions (activities) of the firm are tightly coupled. The completion of one activity event triggers the occurrence of others, like a domino effect. Finally, startup activities differ in their relative importance, depending on the stage of venture development. Some activities are more important at early stages and others are more important at later stages. Previous research has provided empirical evidence for the contextual and individual dependent relationships of new venture creation. For example, Dean and Meyer (1996) found that new venture formation vary according to industry dynamics. Liao and Gartner (2006) suggest that the likelihood of venture persistence increased when nascent entrepreneurs engaged in planning early in the sequence of start-up activities, especially under perceived uncertain financial and competitive environments. The specific organizing activities carried out during the venture gestation process differ among novice, serial, and parallel business founders (Alsos \& Kolvereid, 1998).

Thus, it is expected that the activity pattern of entrepreneurs engage in the firm gestation process is highly contextual and individual dependent. Not all potential startup activities need to be initiated or will be initiated; the time to complete the process will vary; the links between activities will be divergent; and the sequencing patterns of these activities will also differ.

\subsubsection{The Nascent Firm - Founding Strategy (S)}

Entrepreneurs pursue diverse founding strategies that determine new venture emergence. Researchers have used "generalist" (r-strategists) and "specialist" (k-strategists) strategies as the classification scheme for new ventures (Hannan and Freeman, 1977). The generalists offer a wide array of products or services that are aiming at a broad range of customers, whereas the specialists focus on a niche market to avoid direct competition with large and more established firms. However, whether a generalist or specialists strategy leads to a better chance of new venture survival is still an open question (i.e., Romanelli, 1989; Carter, Williams, \& Reynolds, 1997).

Another dimension of founding strategies is market aggressiveness, which is defined as "the depth and rapidity of resource-acquiring activities in either broad or narrow market domains" (Romanelli, 1989, p. 374). Aggressive firms seek to acquire and control as many resources as possible, and as quickly as possible. By contrast, efficient firms seek to protect an established position by using scarce organizational resources. Therefore, it is generally expected that aggressive firms have a higher likelihood of surviving in early years of business development than efficient firms. However, this is not always the case. Li (2001) uses data from 184 ventures in China's high technology industries and found that new venture strategies play differential roles in dealing with different environmental dimensions, thereby affecting performance differently. New ventures are proactive in benign environments, while they become reactive in hostile environments, and the effects of specific founding strategies are environmental dependent.

\subsubsection{The Contexts - Environment (E)}

There has been a long-standing argument about the relative importance of environmental determinism and market conditions at the time of founding as explanations of organizational survival and failure (Hannan \& Carroll, 1992). It is intuitive to think that attractive industries (i.e., growing industries) should make survival easier and therefore have low failure rates. More specifically, Low and Abrahamson (1997) suggested that organizations' operations in growing industries are being viewed as more legitimate than other nascent organizations, therefore, these organizations are more likely to survive.

Competitive concentration, which is calculated as percentage of sales, plant capacity, and distribution channels controlled by the largest four or eight competitors, is related to firm's ability to acquire or increase control of available resources in the industry. Thus, increasing competitive concentration should indicate increased difficulties for young and small firms in acquiring resources and subsequently lead to high failure rates. In support, Dean and Meyer (1996) found that the creation of new ventures are positively related to industry dynamism variables.

Overall, new venture emergence is a context-dependent social process. A new venture formation is rooted within a given context of its environment. Entrepreneurship researchers should pay sufficient attention to the context in which new business are started. Identified factors that lead to entrepreneurial success in one context may lead to failure in another. This is because entrepreneurs undertake specific activities and pursue particular founding strategies in organizing a new venture within its own context of environment. What works in one context for one person will not necessarily work in another. As a consequence, studies examining the independent effects of the factors at the individual, contextual, strategy and process level continue to yield inconclusive findings. It is highly plausible that the effects of variables from one level are to be moderated by variables from the other 
category. For example, the effectiveness of venture gestation process may vary depending on the type of founding strategy and industry condition. Similarly, given different industry conditions, nascent entrepreneurs with different attributes may adopt different venture strategies and subsequently pursue different patterns in gestation process. We need to identify patterns of combinations of factors (configurations) determining new venture creation rather than focusing on specific explanatory factors themselves.

In the next section, the author discusses major drawbacks of conventional configurational approach, and then build a model that uses a qualitative comparative approach to examine the combinative effects of variables from these the above-mentioned four categories.

\section{Qualitative Comparative Approach to Venture Emergence}

\subsection{Conventional Configurational Approach in Methodology}

Because of the multi-dimensional nature of venture formation, the configurational approach is routinely used by researchers as a relevant methodology to study venture creation process. A configurational approach provides a useful insight into entrepreneurial behaviors, but the progress of empirical research remains limited because of using classic linear regression model to examine interaction effects. For example, both two-and three-way interactions, with a number of notable limitations, have been normally used to study configurations in entrepreneurship. Although interaction effect is aimed to overcome this limitation of linear regression model, this approach assumes that interaction effects are relevant for all cases under examination and there is an optimal combination among variables under investigation. This approach largely ignores the fact that different paths may result in the same outcome (Fiss, 2007). Furthermore, traditional approaches to configurational relationships have other drawbacks. First, it is extremely difficult to interpret results when interactions go beyond two-way effects (Fiss, 2007), which essentially limits the number of variables under consideration for configurations. Second, the stability of the results of interactions that involve three or more variables remains an open question (Van de Ven \& Drazin, 1985). Third, the classic linear regression model focuses on the unique contribution of a variable and treats variables as competing alternatives in explaining variation in the outcome by holding other variables constant. It therefore emphasizes the independent, rather than interdependent effects. Fourth, conventional linear regression model shows the extent to which an individual variable is related to an outcome, but it does not take into account how all variables combine to create outcomes. Finally, traditional statistic methods use language to describe correlation between variables, thereby failing to account for necessary and sufficient conditions, the two basic concepts of identifying causal relationships (Fiss, 2007). The combinative impacts of all these factors may render the conventional configurational approach less effective, which calls for qualitative comparative approach to delineate the necessary conditions or configurations under which firm emergence may take place.

\subsection{Qualitative Comparative Approach (QCA)}

Applying QCA approach has important methodological contributions to the extant empirical literature. A common characteristic in the extant empirical literature is that studies mainly focus on partial aspects of new venture emergence and only examine linear contingencies in a specific relationship. First, conceptually, most existing studies on new venture creation assume that new venture creation is a linear, unitary process, which begins with the recognition of a business opportunity and culminates with first sales and first hires. This linear model implies that an additive combination of events will lead to the creation of a new firm (Reynolds \& Miller, 1992; Carter et al., 1996). However, new venture emergence has a strong nature of being context dependent, complex, and heterogeneous, which suggests that simple relationships may be inadequate to explain the whole phenomenon. Thus, multivariate approaches are needed to explore how nascent entrepreneurs, their startup activities and startup process, the competitive environment, and founding strategies combine together influencing the emergence of new ventures. Second, methodologically, most of, if not all, the previous empirical studies mainly relies on a variance-based correlational approach that focuses on the unique contribution of a particular variable by holding constant values of all other variables in the equation (Fiss, 2007). The widely used classical linear regression model treats all explanatory factors as competing in explaining variation of new venture emergence rather than examining effects of combinations. Although some studies have attempted to incorporate multiple contextual variables by employing two way or three interactions to identify configurations and their combinative effects (Dess, Lumpkin, \& Covin, 1997), these approaches place an emphasis on the unique contribution of variance explained by each variable and assume an optimal configuration for venture creation.

Firm emergence could result from different combinations of causal conditions that constitute different factors. To address the limitations of conventional configuration approach, this study employs a qualitative comparative approach to analyze multiple configurations of entrepreneurial characteristics, founding conditions, startup 
strategies, and nascent behaviors. A QCA is uniquely suited to address theoretical arguments, given its advantages in analyzing complex combinations of causes in relation to a particular outcome. It has been widely used in the literature of political science and sociology (Amenta \& Halfmann, 2000; Kvist, 2006), and management (Kogut, MacDuffie, \& Ragin, 2004; Roscigno \& Hodson, 2004; Kogut \& Ragin, 2006).

A qualitative comparative approach considers all possible combinations of causal factors and specifies the configurations of variables that lead to unique outcomes (Ragin, 2000; Ragin, 2006). Compared with the conventional methods used by previous research, a QCA method has a number of significant advantages. Firstly, unlike a linear regression model, a QCA assumes nonlinear relationships and uses Boolean algebra to determine what combination of various variables resulting in firm emergence. Secondly, it stresses the concept of equifinality which assumes that two or more configurations can be equally effective in firm emergence. Equifinality refers to a situation in which the same final state can be achieved by a variety of different paths or from different initial conditions (Ragin, 2000). Put in another way, by centering on the concept of equifinality, QCA assumes that two or more configurations of variables can be equally effective in leading to venture emergence, rather than assumes only one optimal configuration exists. Finally, going beyond traditional two-or three-way interaction effects, a QCA approach can help researchers to identify necessary or sufficient conditions for venture gestation, therefore it enhances our capability of incorporating complex causal relationships into theory building (Fiss, 2007). Therefore QCA distinguishes itself from those conventional methods by emphasizing holisticity, casual complexity, and nonlinearity.

\subsection{Set Theory and Configurations of New Venture Emergence}

Instead of using interaction effects, QCA is based upon classic set theory and uses Boolean algebra to determine what combinations of attributes lead to interested outcomes (Ragin, 2000). The basic idea of set theory is that relationships among different variables are often best understood as set membership (Fiss, 2007). In mathematics, set means a collection of entities, also called elements or members of the set (Zadeh, 1965). Set members can be anything including numbers, people, letters, other sets, and so on. Conventionally, sets are denoted with capital letters. If set $\mathrm{A}$ and $\mathrm{B}$ are equal, it means that they have precisely the same members. If every members of set $\mathrm{A}$ is also a member of set $Z$, then $A$ is said to be a subset of $Z$, (written $A \subseteq Z$ ). If $A$ is a subset of, but not equal to, set $Z$, then $A$ is called a proper subset of $Z$ (written $A \subset Z$ ). Consider a simple case that set $A$ is a member of the set $Z$ (written $A \subset Z$, $A$ is a subset of set $Z$ ). Let $A$ be an entrepreneur who grows up in a self-employment family, and $Z$ be the set of new ventures being successfully created. The statement that people who have self-employment parents tend to successfully create new ventures may be restated as these people form a subset of new venture creation.

A is a subset of $\mathrm{Z}$

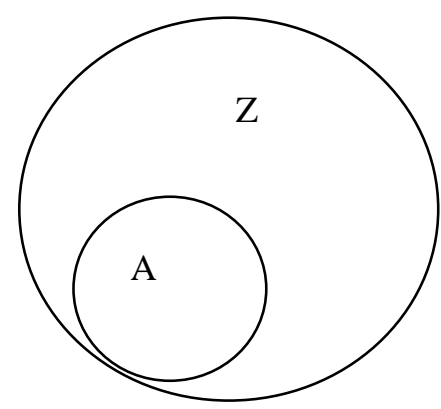

Figure 2. Set $\mathrm{A}$ is a subset of set $\mathrm{Z}$

There are three basic set operations: intersection, union, and complementation. The intersection of two sets is the set containing members common to two sets, denoted by the symbol $\cap$. The union of two sets is the set containing all members belonging to either set or to both, denoted by the symbol $U$. Two sets can also be in complementation, denoted by $\mathrm{B} \backslash \mathrm{A}$, (or B $-\mathrm{A}$ ). It means all members of set $\mathrm{B}$ are not members of $\mathrm{A}$. Now we consider a simple case again. There are many other characteristics may also result in new venture emergence. Consider another set $\mathrm{B}$, a set of individuals with a high rate of startup activities in venture creation process also leads to new venture creation, making set $B$ a subset of successfully created new ventures (written $B \subset Z$ ). It is possible that subset $A$ and $B$ are non-overlap. The union of set $A$ and $B$ result in new venture creation, either set $A$ or $B$ or both implies $Z$ : new venture creation. Thus, if $A=\{1,2,3,4\}$ and $B=\{5,6,7\}$, and $Z$ displays when $A$ $\cup \mathrm{B}=\{1,2,3,4,5,6,7\}$.It may be expressed in the following logic statement:

\section{$\mathrm{A}+\mathrm{B} \rightarrow \mathrm{Z}$}


Where "+" denotes a logical operator "or", and " $\rightarrow$ " denotes a logical implication, meaning "A or B implies Z". In the case of this study, it presents different ways of attaining successful new venture creation: having self-employment parents and engaging in high rate of startup activities.

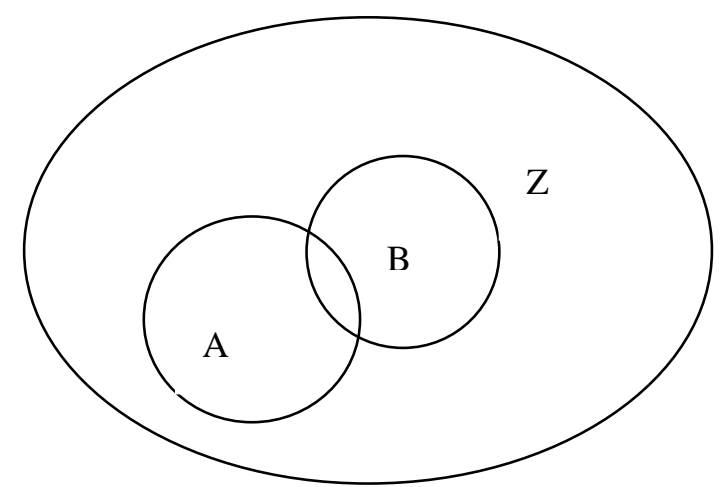

Characteristic $\mathrm{A}$, or $\mathrm{B}$, or both $\mathrm{A}$ and $\mathrm{B}$ can result in outcome of $\mathrm{Z}$.

Figure 3. The union of set $A$ and $B$ is subset of set $Z$

If $\mathrm{Z}$ displays when $\mathrm{A} \cap \mathrm{B}$, it may be expressed in the following logic statement. The relationship is shown in a diagram in Figure 4:

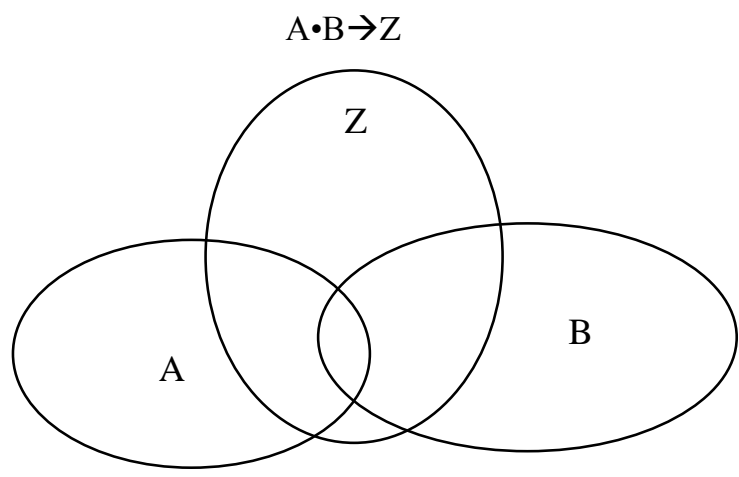

Characteristic $\mathrm{A}$ and $\mathrm{B}$ result in outcome of $\mathrm{Z}$

Figure 4. The intersection of set A and B is subset of $Z$

Now we consider a situation where new ventures $(Z)$ are created by individuals having self-employment parents (A), engaging in high rate of startup activities (B), and under the condition of low competitive environment (C'). Thus, if $A=\{1,2,3,4\}, B=\{5,6,7\}$, and $C^{\prime}=\{3,4,5,6\}$, then $A \cap C^{\prime}=\{3,4\}$, and $B \cap C^{\prime}=\{5,6\}$, and $Z$ displays when $\left(A \cap C^{\prime}\right) \cup\left(B \cap C^{\prime}\right)=\{3,4,5,6\}$. It may be expressed as following logic:

$\mathrm{A} \cdot \sim \mathrm{C}+\mathrm{B} \cdot \sim \mathrm{C} \rightarrow \mathrm{Z}$

Where "॰" denotes a logical operator "and", while " $\sim$ " denotes the logical "not". The above logical statement uses a formulation of a set theory to present a classic contingency hypotheses: $\mathrm{H}_{1}$ : High competitive environment condition moderates the effects of having self-employment parents on new ventures creation; and $\mathrm{H}_{2}$ : High competitive environment condition moderates the effects of engaging in high rate of startup activities on new ventures creation. Thus, the above Boolean statements summarize two contingency statements about the configurational relationships: individual attributes, environment, startup activities, and the outcome of new venture emergence.

Crisp sets are classical sets in set theory. In the crisp sets, all attributes are defined into dichotomous variables (membership versus nonmembership). Each variable only takes value of 1 or 0 , indicating "in" or "out" the set. Classifications of membership in sets rely on the presence of attributes. If $\mathrm{A}=\left\{\mathrm{X}_{1}, \ldots, \mathrm{Xn}\right\}$, for each $x \in A$, the crisp set can be denoted as A $\rightarrow$ (Ragin, 2006).

Crisp sets use Boolean algebra by reconstructing a raw data matrix as a truth table. A truth table treats each case as a combination of the variables chosen by the researcher as causes for a given outcome. Only cases with exactly the same configuration are considered to be the same type of cases. A truth table indicates the number of cases with one configuration and whether or not the outcome occurs along with that configuration. In a truth table, each combination of values on the independent variables is represented as one row. Each row is assigned 
an output value of the dependent variable (a score of 1 or 0 ) along with the number of cases that share such a combination of independent variables. From the truth table, we can get all possible configurations lead to new venture emergence.

\section{Calibration of Variables into Property Space}

\subsection{Sampling}

Data for this study was obtained from the Panel Study of Entrepreneurial Dynamics (PSED). The PSED is a longitudinal data set of individuals in the process of starting businesses who were identified from a random digit dialing telephone survey of 64,622 adults in the United States (Reynolds \& Curtin, 2004a). Details of the survey process and descriptions of specific items in the questionnaires used for the initial and follow-up interviews can be found in the Handbook of Entrepreneurial Dynamics (Gartner, et. al., 2004).

The author followed Reynolds (2007) to select cases into this study. First, retain cases that did not report going into business prior to the initial interview. Then retain cases with at least one follow-up interview; have three or more startup acts; have two startup acts occurred within a 12 month period; and did not report positive monthly cash flow two years prior to any other start-up event. Finally retain cases where initial act was reported less than ten years before the initial interview. This results in the inclusion of 638 nascent startup cases.

\subsection{Measures}

Independent variables were selected at the individual, industry, strategy and process levels that are mostly related to the theoretical concerns. These variables are also described in Table 1.

Table 1. Definitions, Coding, and Means for Variables ( $\mathrm{n}=488$ )

\begin{tabular}{|c|c|c|c|c|}
\hline \multirow[t]{2}{*}{ Variable } & \multirow[t]{2}{*}{ Definition } & \multirow[t]{2}{*}{ Coding } & \multirow[t]{2}{*}{ Mean } & \multirow{2}{*}{$\begin{array}{c}\text { The number of firms } \\
\text { without missing data }\end{array}$} \\
\hline & & & & \\
\hline \multirow[t]{2}{*}{ Firm emergence } & Whether business is operating & $1=$ yes & & 215 \\
\hline & & $0=$ no & .44 & 273 \\
\hline \multicolumn{5}{|l|}{$\begin{array}{l}\text { Venture gestation process } \\
\text {. }\end{array}$} \\
\hline \multirow[t]{2}{*}{$\begin{array}{l}\text { Concentration of startup } \\
\text { activities }\end{array}$} & $\begin{array}{l}\text { High concentration: event-based pacing } \\
\text { High degree to which organizing activities } \\
\text { are clustered. }\end{array}$ & $1=$ high & & 232 \\
\hline & $\begin{array}{l}\text { Low concentration: time-based pacing, the } \\
\text { Activities are widely dispersed. }\end{array}$ & $0=$ low & .48 & 256 \\
\hline \multirow[t]{2}{*}{ Timing } & $\begin{array}{l}\text { Timing late: most of the startup activities } \\
\text { occur at late n gestation process }\end{array}$ & $1=$ late & & 272 \\
\hline & $\begin{array}{l}\text { Timing early: most of the startup activities } \\
\text { occurs at the early stage of gestation process }\end{array}$ & $0=$ early & .56 & 216 \\
\hline \multirow[t]{2}{*}{ Rate of organizing } & $\begin{array}{l}\text { High intensity: there are a greater number of } \\
\text { Activities accomplished for a given period } \\
\text { in time. }\end{array}$ & $1=$ high & & 177 \\
\hline & $\begin{array}{l}\text { Low intensity: a smaller number of activities } \\
\text { accomplished for a given period in time. }\end{array}$ & $0=$ low & .36 & 311 \\
\hline
\end{tabular}

Venture gestation strategy

Strategic aggressiveness High: Intent to start a business that was much

of business more likely to make a millionaire but had a much

$1=$ high 82

Low: intent to start a business that would provide $\quad 0=$ low $\quad .17 \quad 406$

a good living, but with little risk of failure,

and little likelihood of making a millionaire

\section{Entrepreneur's attributes}

Owner Parents

Team

Founding condition

Degree of competition
Parents have worked for themselves or run their own business.

Venture gestation activities conducted by multiple members rather than a single person.

High degree of competition for new business

$\begin{array}{lcc}0=\text { no } & .50 & 244 \\ 1=\text { yes } & & 244 \\ 0=\text { no } & .52 & 232 \\ 1=\text { yes } & & 256 \\ & & \\ 0=\text { low } & .69 & 153 \\ 1=\text { high } & & 335\end{array}$

Firm emergence. Firm emergence was measured by venture status variable by consolidating the four rounds of data collections, Q, R, S, T. Venture status is a self-reported categorical variable, indicating the status of start-up at the time of interviews. The start-up status of "an operating business" was coded as 1 , indicating that firm has 
emerged. The statuses of "still an active start-up, an inactive start-up, no longer being worked by anyone, or something else" are coded as 0 , indicating that firm does not emerge. Since firm emergence could occur at any time during the four rounds of data collections, the author aggregated start-up activities in the four rounds into one firm emergence variable.

Gestation Process. The author followed the methodological approach of Van de Ven and Poole (1989) to code activity measures in the PSED. Eentrepreneur's chronological list of activity events was coded as dichotomous indicators. The PSED lists 26 startup behaviors with questions such as "Have marketing or promotional efforts been started?" If a nascent entrepreneur responded with a "Yes," follow-up questions were asked to document the specific month and year when the activity took place.

A dichotomous indicator was used, with " 1 " representing the presence and "0" the absence of certain informative features of the qualitative event in the venture creation process. For each event, there was a time stamp, including the year and month when the event occurred. For those who could not specifically remember the exact month of the event occurrence, the choices of spring, summer, winter, and fall were offered. And then recoded the season as: Winter equals "1;" Spring equals "4;" Summer equals "7;" and Fall equals "10."

The author followed a procedure by Reynolds and Miller (1992) to create a temporal sequence of events for each nascent entrepreneur. The time that elapsed from the first event to the last event was considered as the gestation period, regardless of the nature of the events. The time stamp for each event was calculated in the following steps: (1) The earliest year and the latest year among all the activities engaged in by an nascent entrepreneur in all four rounds $(\mathrm{Q}, \mathrm{R}, \mathrm{S}, \mathrm{T})$ of data collection were identified. This is viewed as the starting year of a venture gestation process of each nascent. (2) Converted the months and year for each event for all events across the $\mathrm{Q}$, $\mathrm{R}, \mathrm{S}$, and T rounds. (3) If an event occurred in the follow-up interviews, the author kept the time and occurrence for the latest round. For example, if a nascent entrepreneur responded with a "Yes" to the question of "Have marketing or promotional efforts been started?" at Q round and S round, the author kept the time stamp of S round in the dataset. The final dataset has all the consolidated activities engaged in by each nascent entrepreneur coded in bitmap format, with the time stamp in the form of months.

The measurement of concentration, rate and timing is consistent with Lichtenstein et al. (2007). Concentration is measured by the degree to which organizing activities are clustered or spread in time. It is operationalized in terms of the variance of monthly activity time. The smaller the variance, the greater the degree of concentration, that is, activities are highly clustered. The larger the variance, the smaller the degree of concentration, that is, the activities are widely dispersed. Different from Lichtenstein et al. (2007), the author further transformed the variance measures in the following two ways: (1) as the variance for startup activities is large, do a log transformation; (2) to simply the interpretation of these scores, reverse code the log transformed variance by subtracting it from 5. Therefore, the greater the measure is, the greater the degree of concentration. Consistent with Crisp-set requirement, we recode "concentration" into 0 and 1 based on the mean, with 0 for "low concentration" meaning time-based pacing, and 1 for "high concentration" meaning event-based pacing. Rate of organizing is calculated by the total number of events divided by the duration of the gestation time which is the difference between the earliest time and the latest time, regardless of the nature of the event. A greater the rate of organizing will mean there are a greater number of activities accomplished for a given period of time. Similarly we recode "rate" into 0 and 1, with 0 for "low intensity" and 1 for "high intensity". Timing is measured by the average event time divided by the duration of gestation time. A value of timing closer to 0 means most of the startup activities occur at the early stage of gestation process, whereas a value of timing closer to 1 suggests that most of the startup activities occur at late in gestation process. Again, "timing" is recoded into 0 and 1 , with 0 for "doer" (early timing - cent making) and 1 for "thinker" (late timing - sense making).

Individual Attributes. The author included two variables related nascent entrepreneur's demographic characteristics and human capital: owner parents (the parents of nascent entrepreneurs have worked for themselves or run their own business), and entrepreneurial team. Entrepreneurs' parents have self-employed or run their own business were coded 1, while others were coded 0. Entrepreneurial team sizes (the number of all owners) that were more than 1 were coded 1 , while others were coded 0 .

Venture Strategy. One of the most important measures of venture strategy is the measure of the degree of aggressiveness. Strategy literature provides important evidence of measuring strategic intent as a valid proxy measure of strategy. This intent-based measure is particularly salient at the nascent stage when intent would immediately drive the startup behaviors of a nascent entrepreneur. At PSED, each nascent entrepreneur was asked to choose the type of business they intend to start, with alpha for a business with little risk of failure and limited return, and beta for greater risk of failure and greater financial return. The first category is coded as 0 and the latter as 1. 
Industry Conditions. One of most important industry conditions at the nascent stage is the degree of competition within the industry where a startup is taking place. At PSED, each nascent entrepreneur was asked to rank the degree of competition for new business with 0 for no competition, 1 for low competition, 2 for moderate and 3 for strong competition. Then the author recoded the first two categories as 0 for "low competition" and 1 for "high competition.

\section{Evaluation of Calibrated Measures}

Crisp sets of QCA approach have two basic measures evaluating the quality of configurations: consistency and coverage. Consistency is the proportion of cases with a given combinations of attributes in displaying with the given outcome (Ragin, 2006). In our view, consistency measure in QCA is similar to the concept of reliability in traditional statistic measures. It indicates the extent to which an effect of a configuration identified on an outcome has been found to be duplicated among cases that share the same configuration. Coverage score assesses the degree to which a configuration of variables "accounts for" instances of an outcome. Since QCA focuses on the concept of equifinality, it assumes that various configurations are equally effective in creating an outcome of interest. When there are several paths to the same outcome, the coverage of any given causal combination may be small. Coverage indicates the empirical importance of a given path (configuration). Consistency and coverage can be expressed as the following formulas:

Let $\mathrm{Li}: \mathrm{Xi} \rightarrow \mathrm{Zi}, i \in[1, n]$

where $\mathrm{Xi}=\{\mathrm{Ai}, \mathrm{Bi}, \mathrm{Ci} \ldots\}$,

Thus:

$$
\begin{gathered}
\text { Consistency }=\frac{\{L i \mid \mathrm{Xi}=1 \text { and } Z i=1\}}{\{L i \mid X i=1\}} \\
\text { Coverage }=\frac{\{L i \mid X i=1 \text { and } Z i=1\}}{\{L i \mid Z i=1\}}
\end{gathered}
$$

where "L" denotes a list of configurations of characteristics that imply Z among n cases. "X" denotes i subsets of $\mathrm{A}, \mathrm{B}, \mathrm{C}$ displaying value of 1 . Consistency is calculated by examining the percentage of cases displaying an outcome as well as sharing a same configuration of characteristics. Consider a simple example, let us assume the truth table shows three different configurations of the four individual (A), behavior (B), strategic (C), and environmental (D) characteristics that result in new venture emergence $(Z)$. The configurations are listed below:

$$
\begin{aligned}
& \mathrm{L}_{1}: \mathrm{A} \cdot \mathrm{B} \\
& \mathrm{L}_{2}: \mathrm{A} \cdot \sim \mathrm{B} \cdot \mathrm{C} \\
& \mathrm{L}_{3}: \mathrm{A} \cdot \mathrm{B} \cdot \mathrm{C} \cdot \mathrm{D}
\end{aligned}
$$

Thus, all combinations cause new venture emergence: $\mathrm{L}_{1}+\mathrm{L}_{1}+\mathrm{L}_{1} \rightarrow \mathrm{Z}$. Let $\mathrm{n}=100$ for configuration $\mathrm{L}_{1}$ that involves individual (A) and behavior (B) characteristics. If there are 85 out of 100 cases display $\mathrm{Z}$, the consistency score of configuration $\mathrm{L}_{1}$ is as high as .85. Ragin (2006) suggests .75 as a cut-off value for a set-theoretic consistency, otherwise it is difficult to maintain that a subset relation exits (the relation between the configuration and an outcome).

Let the number of all cases displaying new venture creation are 1000, now there are 100 cases are identified for configuration $\mathrm{L}_{1}$, then the coverage score of $\mathrm{L}_{1}$ is .10. If the coverage value for $\mathrm{L}_{2}$ is only .03, it indicates that the $\mathrm{L}_{1}$ is more empirically important than the configuration of $\mathrm{L}_{2}$. In our view, coverage score is similar to the R-square measure in traditional statistic techniques.

It should be kept in mind that "coverage is distinct from consistency, and the two sometimes work against each other because high consistency may yield low coverage"(Ragin, 2006:9). A configuration of causes with perfect consistency is not compelling because it is too narrowly formulated to achieve a large coverage among cases. Therefore, there is always a trade-off between consistency and coverage.

\subsection{Results}

QCA utilizes a Boolean algorithm to assess whether any causal combinations are sufficient to cause the outcome of interest. There are three fundamental operators and notations of Boolean algebra: logical and (symbolized by the operator ·), logical or (symbolized by the operator + ), and logical not (symbolized by the operator $\sim$ ). Logical 
and $(\cdot)$, an operation commonly represents an interaction. It shows that a combination of causal attributes lead to an outcome. Logical or $(+)$ represents the union of other logical sets of the causal attributes involved. It indicates that either one causal condition or another may lead to the same outcome. Logical not (Boolean Negation) presented in the equation represents nonmembership in a set of interest. It switches the membership scores from "1" to "0", and from " 0 " to " 1 ". Combining these three Boolean operators enables researchers to examine complex causality underlying cases. In this study, instead of trying to isolate which individual, strategic, founding environmental, or founding process factors make the largest relative contribution to explaining the variance in new venture formation, QCA allows to examine which individual, strategic, environmental, and process attributes, and any and all combinations of configurations of these attributes, commonly occur across cases that have created new firms.

Table 2. Configurations, Consistency, and Coverage Displayed in Intermediate Solution

\begin{tabular}{|c|c|c|}
\hline Configurations & Unique Coverage & Consistency \\
\hline 1. $\sim$ OWNP $\cdot$ TEAM $\cdot \sim$ TIMING $\cdot$ RATE $\cdot \mathrm{CONC} \cdot \mathrm{COMD}+$ & .07 & .71 \\
\hline 2. OWNP $\sim \sim$ TEAM $\sim$ TIMING $\sim$ RATE $\cdot \sim \mathrm{CONC} \sim \mathrm{COMD} \cdot \sim \mathrm{STRA}+$ & .03 & .78 \\
\hline 3. $\sim$ OWNP $\cdot$ TEAM $\cdot$ TIMING $\sim$ RATE $\sim \mathrm{CONC} \cdot \sim \mathrm{COMD} \cdot \mathrm{STRA}+$ & .01 & .75 \\
\hline 4. OWNP $\cdot \sim$ TEAM $\cdot \sim$ TIMING $\cdot \sim$ RATE $\cdot$ CONC $\cdot \quad$ COMD $\cdot \sim$ STRA & +.03 & .86 \\
\hline 5. $\sim$ OWNP $\cdot$ TEAM $\cdot$ TIMING $\cdot \sim$ RATE $\cdot$ CONC $\cdot$ COMD $\cdot \sim$ STRA & .02 & .71 \\
\hline Solution Coverage: & & \\
\hline Solution Consistency: $\quad .75$ & & \\
\hline
\end{tabular}

Note: OWNP: Owner Parents; CONC: Concentration of Startup Activities; COMD: Degree of Competition; STRA: Strategic Aggressiveness

Table 2 reveals five combinations of individuals, founding environment, startup strategy and process on venture formation. The results show that the overall consistency of reported configurations is .75 , suggesting that among those cases sharing these configurations there are $75 \%$ cases display venture emergence. The individual consistency of each configuration ranges from .71 to .86 . The overall coverage is .17 , indicating that the reported configurations account for $17 \%$ instances of venture emergence.

QCA employs the Boolean algorithm to reduce causal complexity to a minimal Boolean equation of the combinations of attributes. Boolean algorithm first establishes the number of logically possible groupings of attributes included in the study; incorporates all possible causal conditions; assesses the probabilistic sufficiency of each combination of attributes; then uses its containment rule to minimize the Boolean equation of all those combinations. Utilizing Boolean symbols, the results are represented as follows (where $\rightarrow$ denotes Boolean implication):

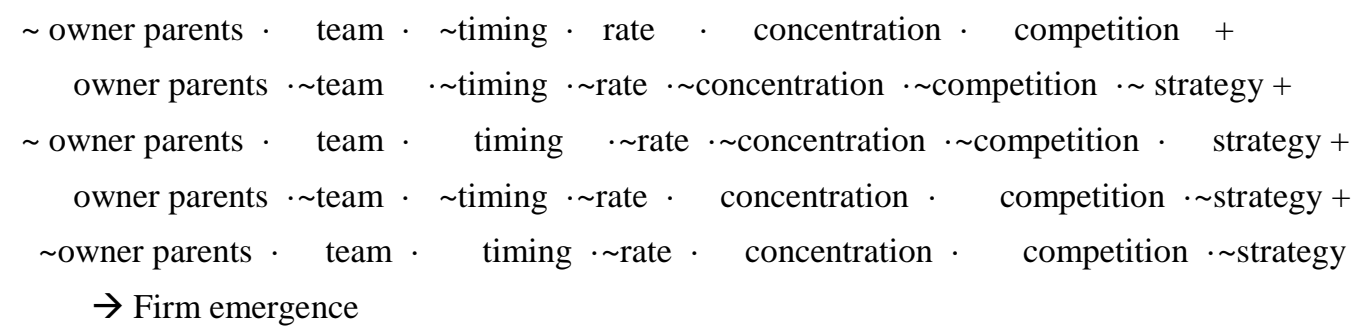

All four categories of interested attributes display in every configuration above, illuminating that individual, strategic, environmental, and founding process attributes commonly occur across cases achieving venture creation. The above results also suggest that five categories of individual, strategic, founding environmental, and venture creation process attributes are usually sufficient for venture formation: "Each equation joined by the operator "." represents a combination of attribute that is usually sufficient for venture emergence" (Greckhamer, Misangyi, Elms, \& Lacey, 2007, p.717).

The operator "+" in the above equations also signifies that there are five alternative combinations of attributes that are sufficient for venture gestation. Each combination allows us to assess which causal factors are important to firm emergence. Recall that in these equations, the " $\sim$ " denotes non-membership in a particular set and it switches the membership scores from " 1 " to " 0 ", and from " 0 " to " 1 ". $~ \sim$ owner parents illuminates "owner parents" is equal to 0: nascent entrepreneurs do not have parents who run their own business. team denotes that all startup activities are conducted by solo nascent entrepreneurs, rather than by a team. timing denotes that most of startup activities occur at the early stage of gestation process, while timing means most of startup activities occur at late in gestation process. rate suggests that there are a smaller number of organizing activities accomplished for a given period of time, while rate means a greater number of activities accomplished at a time. 
concentration denotes a pattern of time-based pacing activities, while concentration suggests event-based pacing venture creation activities. competition illuminates a low degree of competition in the industry. strategy means nascent entrepreneurs pursue a less risky startup strategy, while strategy indicates a great risky startup strategy conducted by nascent entrepreneurs.

The first configuration indicates that in the highly competitive industry, nascent entrepreneurs who do not have strong startup experience compensate their weakness by organizing teams. They perform as "doers" who complete startup activities at the early stage of gestation process, with high intensity of the number of activities at a given period of time, and these activities are highly clustered by showing event-based pacing.

The second configuration suggests that when founding environment is not competitive, nascent entrepreneurs who have owner parents normally create their business solely, with less risky startup strategy. They also act as "doers" who complete activities at early stage, with low intensity of activity accomplishment, and time-based pacing.

The third configuration demonstrates another causal condition of venture gestation. When the industrial competition level is low, entrepreneurial team is formed to compensate entrepreneur's weakness in startup knowledge. Nascent entrepreneurs pursue high risky startup strategy, act as "thinkers" who finish startup activities at late early stage, accomplish smaller number of activities that are widely dispersed.

The fourth configuration involves solo nascent entrepreneurs who create new ventures in highly competitive industrial environment. They pursue less aggressive startup strategy, accomplish startup activities at early stage (doers), conduct smaller number of activities during the venture gestation time, and show an event-based pacing pattern.

The fifth configuration fifth illuminate a pattern of new venture emergence: low level of environmental competition, less aggressive startup strategy, low level of intensity of activities, event-based pacing, entrepreneurial teams that complete activities at the late stage as thinkers.

\section{Discussion and Conclusions}

Patterns in the above five configurations suggest that all individual, strategic, environmental, and process behavioral factors are responsible for venture gestation. The results contributes to the entrepreneurship literature by shedding light on several important aspects: a) factor independence: the importance of single factors at various levels to new venture gestation, b) factor interdependence: the combinations of all factors among entrepreneurs, strategy, environment, and behavior are important to understanding new venture gestation process, and c) factor complex causality underlying the determination of new venture gestation.

First, results illuminate that new venture emergence is a function of individual attributes, venturing strategy, gestation process, and founding environment. All configurations reported in this study involve at least three categorical attributes: individual or team, venture gestation behavior, and founding environment. Although strategy attribute is absent in the first configuration, it display in the rest four configurations, which suggests that strategic factors are very important to venture creation. In general, each factor in the four- category model plays an essential role in venture gestation. Any single changed attribute may constitute a difference in kind that demonstrates a new path to venture formation. For instance, previous literature has acknowledged that new ventures established by solo entrepreneurs are more likely to fail than firms founded by entrepreneurial team, because teams draw upon complementary knowledge of the founders and give them more complete knowledge than single founder ventures (Roberts, 1991; Klepper, 2002). However, results of this study demonstrate that solo founder ventures are equally effective in determining venture formation as team founded ventures, but team or solo founder factors may have different and even opposite effects on venture creation, depending on the contexts. Therefore, a single factor independently matters, but the effectiveness of venture gestation process may rely on the degree to which this factor matches with other factors in a particular context. This leads to the second implication of this study to entrepreneurship literature: factor interdependence.

Consistent with what proposed, the results suggest that the individual effects of variables are moderated by factors at other analytical levels. Results demonstrates factor interdependence among entrepreneurs/ entrepreneurial team, strategy, environment, and venture gestation behavior in determining new venture emergence. The combinations of four categorical attributes are usually sufficient for venture formation. Findings of this study also signify that new venture emergence rarely have a single cause. Put in another way, causes for venture gestation rarely operate in isolation from each other.

Finally, the pattern of the results demonstrates a causal complexity of new venture emergence: a single cause matters in venture gestation; the effectiveness of venture gestation rarely has a single cause; the causes are 
interdependent; and direction of the effect of a specific cause may change with causal conditions. Thus, although the findings show that startup knowledge and venture creation behaviors clearly matter for the outcome of startups, analyses also suggest that the importance of each factor is contingent in the founding environments and types of startup strategy pursued by nascent entrepreneurs. Causal complexity can also be demonstrated by the presence of membership or nonmembership of each of the factors. For instance, membership in owner parents is one of the conditions that are sufficient for venture emergence. However, a nonmembership in owner parents may also be sufficient to the effectiveness of venture gestation in other conditions. Hence, the outcome of venture creation depends on other factors at different levels of analysis, and the effectiveness of outcome could also vary along with the changes in membership or nonmembership in a theoretical set.

\subsection{Limitations and Future Research Directions}

Given its ability to analyze complex conjunctures of cases in relation to a particular outcome, QCA is uniquely suited to address theoretical arguments in the field of entrepreneurship. Although the addition of QCA to the methodologies available to entrepreneurship research is promising, like any methodology, this method has a few caveats which have received considerable attention. Firstly, because of the conditional logic of QCA and the number of possible configurations generated, the method limits the number of independent variables selected. The inclusion of large number of independent variables renders interpretation exponentially unwieldy (Roscigno \& Hodson, 2004). Researchers who use QCA approach are forced to make a rigid selection of a limited number of independent variables that deem theoretical importance. One drawback of this technique is that it depends heavily on theoretical and conceptual developments to define which factors should be included in the analysis. This means that if we do not appropriately specify variables included in the investigation, the results will be invalid.

Secondly, QCA employs probabilistic criteria in capturing complex combination of attributes, however, the generated configurations may due to some degrees of chances; thereby the results may not generalized to different samples including the same variables (Greckhamer et al., 2007). Thus, researchers should examine the robustness of findings by performing a post hoc analysis such as splitting the sector samples into two random subsamples and verify the sufficiency of identified causal conditions. Researchers could also further valid the configurations by testing the configurations in a different set of data. Another approach is to adopt a multi-method strategy and re-estimate the robustness of significant configurations by using conventional quantitative methods (Roscigno \& Hodson, 2004).

Another weakness of QCA is that control variables cannot be included as in the typical regression model. Although a set-theoretic approach has such drawbacks, scholars hold that the benefits of its theoretical rigor in selecting variables, the specification of complex causality and conditional configurations, and the analysis of equifinality outweigh the costs (Boswell \& Brown, 1999; Ragin, 2000).

A final limitation of the current study is that the analysis is constrained in the assessment of crisp-set membership. A drawback of crisp-set QCA is the strict dichotomization of the variables, both dependent and independent ones. Researchers should carefully measure what is present and absent and to what degree and so forth. The future research could also benefit from utilizing "fuzzy sets" that employs qualitative states of full membership and full nonmembership that allow to examine not only difference in kind (yes or no, high or low, as do crisp-sets), but also differences in degree. Fuzzy set allows us to study both qualitative and quantitative variations simultaneously (Ragin, 2000). Thus, future research could consider fuzzy sets in the QCA approach as another appropriate method in entrepreneurship research to study interdependent relationships.

\subsection{Conclusion}

Unlike conventional linear regression models, QCA considers all possible combinations of causal factors and specifies the configurations of variables that lead to unique outcomes. QCA has been identified as an important method that is uniquely suited to address theoretical arguments. This approach has been widely used in other disciplines. This study applied QCA into entrepreneurship and has demonstrated that QCA is a valuable addition to the methodology toolkit of entrepreneurship researchers. From a methodological standpoint, this study has demonstrated the effectiveness of using a QCA approach to examine various configurations and their impacts. The author shows that QCA can advance our understanding of new venture emergence by investigating the interdependent relationships. QCA helps to reveal a causal complexity that is underlying venture emergence.

The present study not only illustrates the potential of using QCA method in entrepreneurship research, but also contributes to theoretical issues that have challenged entrepreneurship scholars. Findings clearly show that there is substantial interdependence among individual, team, behavioral, strategic, and contextual attributes in determining the effectiveness of venture creation. Results reveal five configurations of attributes that are 
sufficient for attaining the same outcome, and any particular factor may have different effects depending on the contingency of other factors.

In the field of entrepreneurship research, there is a clear need to move beyond simple contingency approach, as venture creation faces multiple contingencies such as the entrepreneurs, the opportunity, the context, the process and the outcome, with significant inter-dependence among these contingencies. This paper contributes to both theory building and methodology by providing a configurational view and a combinational approach that goes beyond the conventional correlational view. From a practical standpoint, this study will inform would-be entrepreneurs a holistic view that various paths can lead to the success of firm emergence. This article is hoped to provide insights and severs as a catalyst calling for more studies that combine QCA and conventional methods in the field of entrepreneurship.

\section{References}

Aldrich, H. E. (2012). The emergence of entrepreneurship as an academic field: A personal essay on institutional entrepreneurship. Research Policy, 41(7), 1240-1248. https://doi.org/10.1016/j.respol.2012.03.013

Alsos, G. A., \& Kolvereid, L. (1998). The business gestation process of novice, serial, and parallel business founders. Entrepreneurship: Theory and Practice, 22(4), 101-102.

Amenta, E., \& Halfmann, D. (2000). Wage wars: Institutional politics, WPA wages, and the struggle for US social policy. American Sociological Review, 506-528. https://doi.org/10.2307/2657380

Aragon-Mendoza, J., Raposo, M., \& Roig-Dobón, S. (2016). Gender matters in venture creation decision. Journal of Business Research, 69(6), 2081-2086. https://doi.org/10.1016/j.jbusres.2015.12.012

Boswell, T., \& Brown, C. (1999). The Scope of General Theory Methods for Linking Deductive and Inductive Comparative History. Sociological Methods \& Research, 28(2), 154-185. https://doi.org/10.1177/0049124199028002002

Brüderl, J., Preisendörfe, P., \& Ziegler, R. (1992). Survival chances of newly founded business organizations. American sociological review, 227-242. https://doi.org/10.2307/2096207

Brush, C., Manolova, T., \& Edelman, L. (2008). Properties of emerging organizations: An empirical test. Journal of Business Venturing, 23(5), 547-566. https://doi.org/10.1016/j.jbusvent.2007.09.002

Carter, N., Gartner, W., \& Reynolds, P. (1996). Exploring start-up event sequences. Journal of Business Venturing, 11(3), 151-166. https://doi.org/10.1016/0883-9026(95)00129-8

Carter, N., Williams, M., \& Reynolds, P. (1997). Discontinuance among new firms in retail: The influence of initial resources, strategy, and gender. Journal of Business Venturing, 12(2), 125-145. https://doi.org/10.1016/S0883-9026(96)00033-X

Chuang, A., Hsu, R. S., Wang, A.-C., \& Judge, T. A. (2015). Does West "fit" with East? In search of a Chinese model of person-environment fit. Academy of Management Journal, 58(2), 480-510. https://doi.org/10.5465/amj.2012.1076

Cooper, A. C., \& Daily, C. M. (1997). Entrepreneurial Teams: In D. L. Sexton \& R. W. Smilor (Eds.), Entrepreneurship 2000, chapter 6. Chicago: Upstart Publishing Company.

Cope, J. (2005). Toward a dynamic learning perspective of entrepreneurship. Entrepreneurship theory and practice, 29(4), 373-397. https://doi.org/10.1111/j.1540-6520.2005.00090.x

Davidsson, P., \& Honig, B. (2003). The role of social and human capital among nascent entrepreneurs. Journal of business venturing, 18(3), 301-331. https://doi.org/10.1016/S0883-9026(02)00097-6

Dean, T. J., \& Meyer, G. D. (1996). Industry environments and new venture formations in US manufacturing: A conceptual and empirical analysis of demand determinants. Journal of Business Venturing, 11(2), 107-132. https://doi.org/10.1016/0883-9026(95)00109-3

Dess, G. G., Lumpkin, G. T., \& Covin, J. G. (1997). Entrepreneurial strategy making and firm performance: Tests of contingency and configurational models. Strategic management journal, 677-695. https://doi.org/10.1002/(SICI)1097-0266(199710)18:9<677::AID-SMJ905>3.0.CO;2-Q

Doty, D., \& Glick, W. (1994). Typologies as a unique form of theory building: Toward improved understanding and modeling. Academy of Management Review, 230-251. 
Eckhardt, J. T., \& Shane, S. A. (2013). Response to the commentaries: The individual-opportunity (IO) nexus integrates objective and subjective aspects of entrepreneurship. Academy of Management Review, 38(1), 160-163. https://doi.org/10.5465/amr.2012.0192

Fiss, P. C. (2007). A set-theoretic approach to organizational configurations. Academy of management review, 32(4), 1180-1198. https://doi.org/10.5465/AMR.2007.26586092

Forbes, D., Borchert, P., Zellmer-Bruhn, M., \& Sapienza, H. (2006). Entrepreneurial team formation: an exploration of new member addition. Entrepreneurship theory and practice, 30(2), 225-248. https://doi.org/10.1111/j.1540-6520.2006.00119.x

Gartner, W., \& Liao, J. (2012). The effects of perceptions of risk, environmental uncertainty, and growth aspirations on new venture creation success. Small Business Economics, 39(3), 703-712. https://doi.org/10.1007/s11187-011-9356-1

Gartner, W., Starr, J., \& Bhat, S. (1999). Predicting new venture survival: an analysis of "anatomy of a start-up." cases from Inc. Magazine. Journal of Business Venturing, 14(2), 215-232. https://doi.org/10.1016/s0883-9026(97)00063-3

Gartner, W. B. (1985). A conceptual framework for describing the phenomenon of new venture creation. Academy of management review, 10(4), 696-706.

Gatewood, E. J., Shaver, K. G., \& Gartner, W. B. (1995). A longitudinal study of cognitive factors influencing start-up behaviors and success at venture creation. Journal of business venturing, 10(5), 371-391. https://doi.org/10.1016/0883-9026(95)00035-7

Gimeno, J., Folta, T. B., Cooper, A. C., \& Woo, C. Y. 1997. Survival of the fittest? Entrepreneurial human capital and the persistence of underperforming firms, Administrative Science Quarterly, 750-783. https://doi.org/10.2307/2393656

Greckhamer, T., Misangyi, V. F., Elms, H., \& Lacey, R. (2007). Using qualitative comparative analysis in strategic management research: An examination of combinations of industry, corporate, and business-unit effects. Organizational Research Methods.

Gruber, M., MacMillan, I. C., \& Thompson, J. D. (2013). Escaping the prior knowledge corridor: What shapes the number and variety of market opportunities identified before market entry of technology start-ups? Organization Science, 24(1), 280-300. https://doi.org/10.1287/orsc.1110.0721

Haber, S., \& Reichel, A. (2007). The cumulative nature of the entrepreneurial process: The contribution of human capital, planning and environment resources to small venture performance. Journal of Business Venturing, 22(1), 119-145. https://doi.org/10.1016/j.jbusvent.2005.09.005

Hannan, M., \& Carroll, G. (1992). Dynamics of organizational populations: Density, legitimation, and competition: Oxford University Press, USA.

Jones, O., \& Holt, R. (2008). The creation and evolution of new business ventures: an activity theory perspective. Journal of small business and enterprise development, 15(1), 51-73. https://doi.org/10.1108/14626000810850847

Klepper, S. (2002). The capabilities of new firms and the evolution of the US automobile industry. Industrial and corporate change, 11(4), 645-666. https://doi.org/10.1093/icc/11.4.645

Klotz, A. C., Hmieleski, K. M., Bradley, B. H., \& Busenitz, L. W. (2014). New venture teams a review of the literature and roadmap for future research. Journal of Management, 40(1), 226-255. https://doi.org/10.1177/0149206313493325

Kogut, B., MacDuffie, J. P., \& Ragin, C. (2004). Prototypes and strategy: Assigning causal credit using fuzzy sets. European Management Review, 1(2), 114-131. https://doi.org/10.1057/palgrave.emr.1500020

Kogut, B., \& Ragin, C. (2006). Exploring complexity when diversity is limited: Institutional complementarity in theories of rule of law and national systems revisited. European Management Review, 3(1), 44-59. https://doi.org/10.1057/palgrave.emr.1500048

Korunka, C., Frank, H., Lueger, M., \& Mugler, J. (2003). The entrepreneurial personality in the context of resources, environment, and the startup process-A configurational approach. Entrepreneurship theory and practice, 28(1), 23-42. https://doi.org/10.1111/1540-8520.00030 
Kvist, J. 2006. Diversity, ideal types and fuzzy sets in comparative welfare state research, Innovative Comparative Methods for Policy Analysis: Beyond the quantitative-qualitative divide,167-184: New York: Springer.

Li, H. (2001). How does new venture strategy matter in the environment-performance relationship? The journal of high technology management research, 12(2), 183-204. https://doi.org/10.1016/S1047-8310(01)00036-0

Lichtenstein, B. B., Carter, N. M., Dooley, K. J., \& Gartner, W. B. (2007). Complexity dynamics of nascent $\begin{array}{llll}\text { entrepreneurship. Journal of Business } & \text { Venturing, 236-261. }\end{array}$ https://doi.org/10.1016/j.jbusvent.2006.06.001

Low, M. B., \& Abrahamson, E. (1997). Movements, bandwagons, and clones: Industry evolution and the entrepreneurial process. Journal of Business Venturing, 12(6), 435-457. https://doi.org/10.1016/S0883-9026(97)00001-3

Low, M. B., \& MacMillan, I. C. (1988). Entrepreneurship: Past Research and Future Challenges. Journal of Management, 14(2), 139-161. https://doi.org/10.1177/014920638801400202

Meyer, A., Tsui, A., \& Hinings, C. (1993). Configurational approaches to organizational analysis. Academy of Management Journal, 1175-1195. https://doi.org/10.2307/256809

Phillips, N., Tracey, P., \& Karra, N. (2013). Building entrepreneurial tie portfolios through strategic homophily: The role of narrative identity work in venture creation and early growth. Journal of Business Venturing, 28(1), 134-150. https://doi.org/10.1016/j.jbusvent.2011.12.002

Ragin, C. (2006). Set relations in social research: Evaluating their consistency and coverage. Political Analysis, 14(3), 291-310. https://doi.org/10.1093/pan/mpj019

Ragin, C. C. (1987). The comparative method: Moving beyond qualitative and quantitative strategies: University of California Press.

Ragin, C. C. (2000). Fuzzy-set social science: University of Chicago Press.

Reynolds, P., \& Miller, B. (1992). New firm gestation: Conception, birth, and implications for research. Journal of Business Venturing, 7(5), 405-417. https://doi.org/10.1016/0883-9026(92)90016-K

Roberts, E. B. (1991). Entrepreneurs in high technology: Oxford University Press, USA. https://doi.org/10.1093/acprof:oso/9780195067040.001.0001

Romanelli, E. (1989). Environments and strategies of organization start-up: Effects on early survival, Administrative Science Quarterly, 369-387. https://doi.org/10.2307/2393149

Roscigno, V. J., \& Hodson, R. (2004). The organizational and social foundations of worker resistance. American sociological review, 69(1), 14-39. https://doi.org/10.1177/000312240406900103

Shapero, A., \& Giglierano, J. (1982). Exits and entries: A study in yellow pages journalism. Frontiers in entrepreneurship research, 113-141.

Shook, C. L., Priem, R. L., \& McGee, J. E. (2003). Venture creation and the enterprising individual: A review and synthesis. Journal of Management, 29(3), 379-399. https://doi.org/10.1016/S0149-2063(03)00016-3

Starr, J., \& Bygrave, W. (1991). The second time around: The outcomes, assets and liabilities of prior start-up experience. International perspectives on entrepreneurship research, 340-363.

Van de Ven, A. H., \& Drazin, R. (1985). The concept of fit in contingency theory. Research in Organizational Behavior, 7, 333-365.

Van de Ven, A. H., Hudson, R., \& Schroeder, D. M. (1984). Designing new business startups: Entrepreneurial, organizational, and ecological considerations. Journal of management, 10(1), 87-108. https://doi.org/10.1177/014920638401000108

Zadeh, L. (1965). Fuzzy sets. Information and control, 8, 338-353. https://doi.org/10.1016/S0019-9958(65)90241-X

\section{Copyrights}

Copyright for this article is retained by the author(s), with first publication rights granted to the journal.

This is an open-access article distributed under the terms and conditions of the Creative Commons Attribution license (http://creativecommons.org/licenses/by/4.0/). 